\title{
Judicialización de los conflictos ambientales en el departamento del Chocó: ríos de mercurio*
}

\author{
[Artículos]
}

\author{
Yeicy Lorena Echavarría-Rentería ${ }^{* *}$ \\ Lisneider Hinestroza-Cuesta***
}

Recibido: 10 febrero de 2021

Aceptado: 6 de mayo de 2021

Citar como:

Echavarría-Rentería, Y. L. e Hinestroza-Cuesta, L. (2021). Judicialización de los conflictos ambientales en el Chocó: ríos de mercurio. Revista IUSTA, (55). https://doi.org/10.15332/25005286.6852

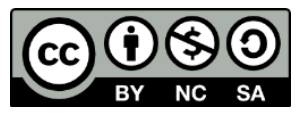

\footnotetext{
* Este artículo es resultado del proyecto de investigación "Estudio jurídico sobre los mecanismos de resolución pacífica de conflictos en las comunidades negras de la cuenca del río Atrato como estrategia para garantizar la construcción de paz, los derechos de las comunidades y del río", adscrito al Grupo de Investigación Derecho, Sociedad y Medio Ambiente de la Universidad Tecnológica del Chocó Diego Luis Córdoba (UTCH), Colombia. Proyecto financiado en el marco de las convocatorias internas para el Fortalecimiento de los Procesos e Indicadores de Investigación Institucional y Vinculación de Jóvenes Investigadores UTCH del año 2019.

** Abogada, magíster en Derechos Humanos y Cultura de Paz de la Pontificia Universidad Javeriana, Colombia. Joven Investigadora del Grupo de Investigación Derecho, Sociedad y Medio Ambiente de la Universidad Tecnológica del Chocó (UTCH), Colombia. Fue Consultora de la Organización Internacional para las Migraciones (OIM). Correo electrónico: yeicyecharente@gmail.com; ORCID: https://orcid.org/0000-00033654-4889

*** Abogada, magíster en Derecho de los Recursos Naturales y doctora en Derecho de la Universidad Externado de Colombia. Líder del Grupo de Investigación Derecho Sociedad y Medio Ambiente de la Facultad de Derecho de la Universidad Tecnológica del Chocó (UTCH), Colombia, donde también ejerce como docente, adscrita a la Vicerrectoría de Investigaciones-Centro de Investigaciones en Biodiversidad y Hábitat UTCH. Correo electrónico: lisneider@yahoo.es; ORCID: https://orcid.org/0000-00033580-1716
}

\section{Revista IUSTA}

ISSN: 1900-0448 | e-ISSN: 2500-5286 | DOI: https://doi.org/10.15332/25005286 


\section{Resumen}

En Colombia se registra una escalada exponencial de los conflictos ambientales, ocasionada por el uso y explotación intensivos de los recursos naturales, lo que ha generado una crisis ambiental poco visibilizada, en parte por el modelo económico neoextractivista adoptado por el país. En el departamento del Chocó, uno de los lugares con mayor biodiversidad en Colombia y el mundo, la minería ilegal mecanizada y el conflicto armado interno han generado graves impactos ambientales y sociales, que han afectado especialmente las fuentes hídricas. Este departamento es habitado mayoritariamente por comunidades negras e indígenas, que han visto vulnerados su territorio ancestral, su forma de vida y sus derechos, a causa de la explotación indiscriminada de los recursos naturales. Mediante una investigación exploratoria, documental y analítico-descriptiva, este artículo se enfoca en identificar los principales conflictos socio-ambientales relacionados con fuentes hídricas que fueron judicializados en los últimos años en el departamento del Chocó, caracterizarlos, determinar sus principales actores y efectos, y determinar la efectividad de la vía judicial para resolver este tipo de conflictos. Se concluye que es urgente que el Estado colombiano reconozca y garantice el ejercicio de los mecanismos propios de resolución de conflictos de las comunidades negras, los cuales son una herramienta efectiva para resolver controversias de tipo ambiental y garantizar el acceso a la justicia en las regiones más apartadas del país.

Palabras clave: comunidades negras, conflictos socioambientales, fuentes hídricas, impacto ambiental, judicialización, mecanismos de resolución de conflictos, minería ilegal.

\section{Judicialization of environmental conflicts in the department of Chocó: rivers of mercury}

\section{Abstract}

In Colombia, there is an exponential escalation of environmental conflicts, caused by the intensive use and exploitation of natural 
resources, which has generated an environmental crisis with little visibility, partly due to the neo-extractivist model adopted by the country. In the department of Chocó, one of the most biodiverse places in Colombia and the world, illegal mechanized mining and the armed conflict have generated serious environmental and social impacts, especially affecting water sources. This department is inhabited especially by black and indigenous communities, who have seen their ancestral territory, their way of life and their rights violated due to the indiscriminate exploitation of natural resources. Through an exploratory, documentary and analytical-descriptive research, this article focused on identifying the main socio-environmental conflicts related to water sources that were brought to court in recent years in the department of Chocó, characterizing them, determining their main actors and effects, and determining the effectiveness of the judicial process to resolve this type of conflict. The paper concluded that it is urgent for the Colombian State to recognize and guarantee the exercise of the black communities' own conflict resolution mechanisms, which are an effective tool for resolving environmental disputes and guaranteeing access to justice in the most remote regions of the country.

Keywords: black communities, socio-environmental conflicts, water sources, environmental impact, judicialization, conflict resolution mechanisms, illegal mining.

\section{Judicialização dos conflitos ambientais em Chocó, Colômbia: rios de mercúrio}

\section{Resumo}

Na Colômbia, é registrada um crescimento exponencial dos conflitos ambientais, ocasionado pelo uso e pela exploração intensivos dos recursos naturais, o que tem gerado uma crise ambiental pouco visibilizada, em parte pelo modelo neoextrativista adotado pelo país. No estado do Chocó, um dos lugares com maior biodiversidade na Colômbia e no mundo, a mineração ilegal mecanizada e o conflito armado interno 
vêm gerando graves impactos ambientais e sociais que afetam especialmente as fontes hídricas. Essa região é habitada especialmente por comunidades negras e indígenas, que veem violados seu território ancestral, sua forma de vida e seus direitos, devido à exploração indiscriminada dos recursos naturais. A partir de uma pesquisa exploratória, documental e analítico-descritiva, neste artigo, foca-se na identificação dos principais conflitos socioambientais relacionados com fontes hídricas que foram judicializados nos últimos anos em Chocó, caracterizá-los, determinar seus principais atores e efeitos, e determinar a efetividade da via judicial para resolver esse tipo de conflitos. Concluise que é urgente que o Estado colombiano reconheça e garanta o exercício dos mecanismos próprios de resolução de conflitos das comunidades negras que são uma ferramenta efetiva para resolver controvérsias de tipo ambiental e garantir o acesso à justiça nas regiões mais afastadas do país.

Palavras-chave: comunidades negras, conflitos socioambientais, fontes hídricas, impacto ambiental, judicialização, mecanismos de resolução de conflitos, mineração ilegal.

\section{Introducción}

Los conflictos ambientales son tan antiguos como el ser humano, en la actualidad todos ponen sus ojos sobre ellos en vista de los graves impactos que ha generado el modelo económico extractivista en el planeta, muchos grupos sociales alrededor del mundo reclaman justicia ambiental para lograr transformaciones en el uso y aprovechamiento de los recursos naturales (Pardo, 2014). En las últimas décadas son múltiples los conflictos de este tipo que han llamado la atención del mundo, por ejemplo, el petróleo que contamina el delta del Níger en Nigeria, los vertidos mineros tóxicos que sepultan la región de Samarco, Minas Gerais, en Brasil, pueblos del cáncer en China, minas de carbón que destruyen sitios sagrados en Sudáfrica, acaparamiento de tierras mortal en 
Guatemala, vertidos ilegales de residuos tóxicos en Somalia, centrales nucleares en España, el viento que se llevó el bosque Kallpavalli en India (Cerrillo, 2016), entre otros. Los conflictos mencionados, a pesar de su importancia, son solo una pequeña muestra de los problemas ambientales que se generan constantemente alrededor del planeta, pues estos tienden a escalar en los años posteriores, de ahí la importancia de que los Estados de todo el mundo implementen políticas públicas en pro de la gestión oportuna de estos conflictos.

El Estado colombiano no puede ser ajeno a este llamado, dado que, por su biodiversidad y riqueza natural, el país es un escenario propenso para la reproducción de conflictos ambientales, además, el modelo económico extractivista implementado en los distintos gobiernos de turno ha generado graves impactos en el ambiente natural y en la población de determinadas regiones del territorio nacional (Mosquera y González, 2020). Asimismo, la incidencia de los grupos armados ilegales en la reproducción y escalamiento de estos conflictos es bastante alta, pues estos se han convertido en un actor determinante dentro de dichas controversias, lo que genera un reto mayor a la hora de encontrar mecanismos adecuados para la gestión de estos conflictos. De manera que cada vez es más urgente que el Estado colombiano implemente políticas públicas que permitan prevenir y transformar los conflictos ambientales que a su vez tienen raíces sociales profundas. Como lo manifiesta Rodríguez y Ibáñez (2019), el Estado colombiano debe asumir un papel protagónico, orientado por las políticas públicas, para dar un tratamiento adecuado a los conflictos relacionados con los recursos naturales y el medio ambiente.

El departamento del Chocó, ubicado en el Pacífico colombiano, es uno de los lugares en el mundo con mayor biodiversidad, está poblado principalmente por comunidades negras e indígenas, que en su mayoría se 
encuentran localizadas en la rivera de los ríos; estas comunidades ancestralmente han mantenido una estrecha relación con el territorio y los recursos naturales. Sin embargo, el Chocó ha sido por décadas objeto de una explotación indiscriminada de recursos naturales como madera, oro y platino, que data de la época de la Colonia, cuando los negros esclavizados perecían en las minas de la región. En la actualidad, debido a la minería ilegal indiscriminada, la presencia de grupos armados ilegales y la vulneración sistemática de derechos humanos a la población negra e indígena, el Chocó se encuentra sumergido en una grave crisis socioambiental. Como dicen Londoño y Polindara (2019):

El departamento del Chocó ha sido objeto históricamente de proyectos extractivistas que lo consideran como una oportunidad inagotable de recursos naturales y materia prima, donde además existe una fuente de mano de obra barata por las complejas situaciones socioeconómicas en las que vive su población. (p. 291)

De ahí que este departamento se ha convertido en un cultivo para los conflictos ambientales, relacionados principalmente con los impactos de la minería ilegal que se practica indiscriminadamente en el territorio. Frente a la delicada situación ambiental del Chocó, se han pronunciado distintos órganos judiciales de orden nacional y regional, como la Corte Constitucional, el Consejo de Estado, el Tribunal Administrativo de Cundinamarca y el Tribunal de lo Contencioso Administrativo del Chocó, que mediante fallos, como la icónica Sentencia T-622 de 2016, han intentado crear una ruta para encontrar soluciones a los conflictos ambientales que se presentan en esta región del país. Sin embargo, es importante tener en cuenta que la vía judicial es solo una forma o mecanismo para la resolución de este tipo de conflictos, que no siempre resulta adecuada, dado que estas controversias también pueden ser tramitadas por la vía administrativa o a través de los mecanismos 
ancestrales de resolución de conflictos, como expresión del derecho propio de los grupos étnicos.

Partiendo de este contexto, el objetivo del presente artículo es identificar los principales conflictos socio-ambientales que fueron judicializados en los últimos quince años en el departamento del Chocó, caracterizarlos y conocer sus principales actores y efectos, de manera que sea posible determinar si esta vía es la más expedita para la gestión y resolución de este tipo de conflictos.

La atención de los conflictos ambientales debe ser un asunto urgente para el Estado colombiano en sus niveles central y descentralizado, que debe poner en marcha la implementación de políticas públicas que atiendan estas problemáticas. En este sentido, esta investigación resulta fundamental para el país en cuanto permite visibilizar la situación particular del Chocó en materia de conflictos ambientales, con el propósito de que las autoridades competentes y todos los actores involucrados emprendan acciones para la prevención y gestión de estas controversias. La reflexión que se propone se desarrolla en tres partes, en la primera, se definen los conflictos ambientales y su potencial transformador, al poner en evidencia problemas sociales estructurales, además, se analizan los impactos de este tipo de conflictos en los grupos étnicos; en la segunda, se caracterizan los conflictos ambientales sometidos a la vía judicial en los últimos años en el departamento del Chocó, lo que permitirá determinar el alcance de dichas controversias; finalmente, en la tercera parte se presentan las conclusiones.

\section{Metodología}

La investigación en la que se fundamenta este artículo se desarrolló en tres etapas. En un primer momento, se realizó una revisión documental de 
artículos científicos, literatura y jurisprudencias sobre la naturaleza y tipologías de los conflictos ambientales. En un segundo momento, se solicitó al Tribunal de lo Contencioso Administrativo del Chocó y a los juzgados administrativos de Quibdó copia de los expedientes judiciales (acciones populares y de grupo) que reposan en sus despachos y versan sobre controversias socio-ambientales, gracias a esto fue posible identificar un total de 22 conflictos ambientales (3 acciones populares y 19 acciones de grupo sobre la contaminación de las fuentes hídricas en el Chocó) ${ }^{1}$. Para finalizar, se identificó la necesidad de que el Estado asuma la crisis socioambiental que atraviesa el país, genere herramientas para la operatividad de la vía judicial (justicia ambiental y jurisdicción especializada) y reconozca la afectividad del derecho propio de las comunidades negras del departamento del Chocó, a partir del ejercicio de sus mecanismos ancestrales de resolución de conflictos.

\section{Conflictos ambientales}

Los conflictos ambientales se generan porque distintos grupos sociales tienen una perspectiva diferente frente al uso y goce de los recursos naturales, para Rodríguez (2016), los conflictos ambientales son comprendidos como la lucha de carácter socioeconómico y político entre distintos actores, que se genera por la presencia de diversos intereses conexos con el aprovechamiento, protección, administración, uso, explotación, afectación y conservación de los recursos naturales. Los principales protagonistas de este tipo de conflicto son las instituciones del Estado, las empresas nacionales e internacionales, las organizaciones sociales y los grupos étnicos.

${ }^{1}$ Oficio n. 2057 del 13 de diciembre del 2019, Tribunal de lo Contencioso Administrativo del Chocó. 
Los conflictos ambientales tienen el poder de visibilizar problemáticas sociales, relacionadas con la desigualdad e inequidad que soportan determinados grupos poblacionales. En esto consiste el potencial transformador que tienen los conflictos, pues, si se analizan profundamente, se podrá observar que estos no solo están relacionados con la disputa por el aprovechamiento y propiedad de los recursos naturales, sino que aluden a problemas sociales estructurales (relación Estado-periferia, exclusión, discriminación racial, lucha de clases, crisis democrática, entre otros). De manera que la resolución de este tipo de conflictos implica un mayor esfuerzo, ya que no se trata solo de determinar quién tiene la propiedad, uso y aprovechamiento de los recursos naturales, sino que se requiere realizar reformas sociales, económicas y políticas estructurales.

Los grupos étnicos se han convertido en uno de los principales actores pasivos en los conflictos ambientales en todo el mundo, pues estos tienen una cosmovisión donde las economías extractivistas no tienen un lugar determinante para el desarrollo humano, visión que va contra los intereses económicos de los Estados modernos, quienes en la mayoría de los casos basan su crecimiento económico en la explotación de los recursos naturales. Para autores como Sabatini es necesario abordar los conflictos ambientales desde una perspectiva más amplia, este autor afirma que "los conflictos ambientales actuales son mucho más que meras disputas por la propiedad de un recurso. En ellos se encuentran enfrentadas cosmovisiones ambientales y de vida" (Sabatini, citado por Walter, 2009, p. 4). De manera que las disputas ambientales no solo están relacionadas con la administración y uso de los recursos, sino que van más allá de intereses económicos, pues tras un conflicto de carácter ambiental entran en juego otros intereses, es decir, se genera una disputa entre formas de 
percibir, apreciar y concebir el ambiente en general (Güiza y Palacios, citados por Güiza, Londoño, Rodríguez y Zuluaga, 2015).

Los grupos étnicos en Colombia se han caracterizado por reclamar la defensa de su territorio ancestral frente a la implementación de proyectos de explotación de recursos naturales y afectación al medio ambiente. Las comunidades negras e indígenas históricamente han desarrollado un vínculo con su territorio, al que no solo consideran una porción de tierra, sino un ente de vida, donde las comunidades han construido un vínculo con el ecosistema que las rodea y tienen la oportunidad de desarrollarse desde su cosmovisión. Como dicen Hinestroza, Mena y Tello (2019):

La tendencia cuando se trata de grupos étnicos, principalmente de comunidades negras e indígenas, es reconocer que el concepto de tierras es restringido, mientras que el concepto de territorio es amplio, integral, y bajo ese concepto se permite el desarrollo de la vida, la identidad, las prácticas tradicionales y de producción; la tierra es uno de los elementos primordiales del territorio, hace parte de la visión del territorio. (pp. 160-161)

\section{La judicialización de los conflictos ambientales en el departamento del Chocó}

En Colombia, durante las últimas décadas el tema ambiental ha permeado el ámbito jurídico, prueba de esto es una serie de instrumentos jurídicos que permite que los ciudadanos demanden las controversias socioambientales, entre estos se encuentran las acciones públicas de inconstitucionalidad y las acciones de tutela - populares y de grupo-. Entre estos, la primera es de conocimiento directo de la Corte Constitucional y las otras tres de la justicia ordinaria y contenciosa administrativa, dependiendo de la naturaleza del agente que presuntamente generó el perjuicio medioambiental. Es así que los jueces en Colombia han tenido que analizar un significativo número de conflictos 
ambientales y, en últimas, han intervenido a través de sus fallos para garantizar el derecho a un medio ambiente sano (Rodríguez, 2019). Aparte de las acciones constitucionales mencionadas, en la jurisdicción ordinaria existen figuras jurídicas por las que se puede acusar la defensa de los recursos naturales y el medio ambiente: en materia civil se encuentra el proceso de responsabilidad civil extracontractual (Código Civil Colombiano, Art. 2341), mediante el cual se puede solicitar la reparación del daño ambiental individual; en materia penal se encuentra el Capítulo Único del Título XI del Código Penal Colombiano que figura bajo el rótulo "De los delitos contra los recursos naturales y el medio ambiente". Igualmente, en el caso de la jurisdicción Contenciosa Administrativa, existen figuras de orden legal, mediante las cuales se pueden tramitar asuntos medioambientales: es el caso de la demanda de nulidad para disposiciones o actos de orden generales y la de nulidad y restablecimiento del derecho para aquellos actos de carácter individual.

Para el trámite de asuntos socio-ambientales la Jurisdicción Contenciosa Administrativa es determinante, pues, de acuerdo con Valencia (2011), la legislación ambiental tiene una naturaleza eminentemente administrativa debido a que el Estado es un actor decisivo en este tipo de controversias. Además, según Rodríguez (2019), en la actualidad la Jurisdicción Contenciosa Administrativa es la encargada de resolver la mayoría de las controversias jurídicas de índole ambiental, pues el derecho medioambiental responde a un carácter preminentemente público, ligado al campo del derecho administrativo. En este orden de ideas, resulta inconsecuente la resolución de este tipo de conflictos por la jurisdicción ordinaria civil (Palomares, 2015).

Por lo anterior, en el presente estudio se consideró analizar los conflictos ambientales presentados ante la Jurisdicción Contenciosa Administrativa en el departamento del Chocó, dado que mediante esta jurisdicción es 
posible evidenciar la incidencia del Estado en este tipo de conflictos; además, permite auscultar los problemas sociales estructurales que están incidiendo en el desarrollo de los conflictos ambientales, considerando que muchos de estos tienen sus raíces en problemas sociales desatendidos por el mismo Estado.

El departamento del Chocó no es ajeno a la tendencia de judicializar los conflictos ambientales, pues el impacto ambiental y social que ha generado la minería mecanizada en el Chocó es alarmante, como dicen García y Varón (2018), "el departamento del Chocó se encuentra sumergido en una crisis humanitaria, sociocultural y ambiental ignorada reiterativamente por el Estado colombiano" (p. 300). Igualmente, el Centro de Estudios para la Justicia Social Tierra Digna (Melo, 2015) establece que el Ministerio Público, mediante la Defensoría del Pueblo, se mostró de acuerdo con que en el Chocó existe una crisis socioambiental ocasionada por la explotación ilegal de platino y oro, que ha generado una amenaza contra el patrimonio ambiental, así como el surgimiento de distintos conflictos que han ocasionado graves afectaciones a la población de la región.

En este sentido, recientemente la vía judicial se ha convertido en un mecanismo utilizado por las comunidades étnicas, organizaciones sociales y no gubernamentales para reclamar mediante acciones constitucionales (acciones de tutela, de grupo y populares) la protección del medio ambiente, el territorio y la identidad cultural, considerando que el departamento del Chocó se encuentra en su mayoría habitado por comunidades negras e indígenas, que se ven gravemente afectadas por los daños ambientales generados en sus territorios, al punto de correr el riesgo de perder sus costumbres e identidad cultural, e incluso su propia vida. 
La explotación ilegal de minerales (oro y platino) en el Chocó es la principal causa de los conflictos ambientales en este departamento, considerado por muchos como una reserva natural inagotable. El principal recurso afectado en estas controversias es el agua, como se verá en los casos objeto de estudio, pues, en los últimos años, las fuentes hídricas del Chocó están siendo contaminadas indiscriminadamente por la minería ilegal mecanizada. Frente al tema ya se han proferido distintos fallos judiciales, considerando que la afectación al ambiente y a las comunidades étnicas es desproporcionado. Uno de los más renombrados es la Sentencia T-622 de 2016 (relacionada con el río Atrato) proferida por la Corte Constitucional de Colombia.

En este pronunciamiento la Corte le otorga el carácter de sujeto de derecho al río Atrato, después de que autoridades étnico territoriales y organizaciones sociales, mediante acción de tutela demandaran la extracción minera y forestal ilegal indiscriminada, que se realiza con retroexcavadoras, dragas y sustancias fuertemente tóxicas como el mercurio. En esta Sentencia la Corte determinó que la contaminación del río Atrato vulneraba los derechos fundamentales a la vida, al agua, a la salud, a la cultura, al medio ambiente sano, a la seguridad alimentaria y al territorio de las comunidades étnicas que habitan la cuenca del río (C.C., Sentencia T-622/2016, Colom.).

La llamada Sentencia del río Atrato presenta una visión ecocéntrica, que concibe a la naturaleza como un auténtico sujeto de derecho, es decir, como sujeto de protección, conservación, mantenimiento y restauración (C.C., Sentencia C-632/2011, Colom.), como dice Briceño (2017):

La ética ecológica se formula, en ocasiones, a partir de la noción de ecosistema, considerándose la naturaleza en sí misma y el hombre como parte de ese sistema. Se trata de proponer el equilibro entre el orden social y el ecosistema, asignándose un valor a todos los elementos que 
componen ambas esferas. Se atribuye a la naturaleza un valor intrínseco, independiente de los valores humanos. (pp. 106-107)

Esta postura ha significado un avance desde las concepciones clásicas, donde el único sujeto de derecho es el hombre, quien puede entender y comprender racionalmente el sistema jurídico que lo rige. De ahí que esta visión permita replantear la comprensión de los conflictos ambientales, pues se parte de la concepción de que los conflictos ambientales, se generan entre los hombres, ya sea por la conservación, explotación y uso de los recursos naturales, sin embargo, esta postura muestra que el conflicto también se puede generar entre el hombre y el ecosistema que lo rodea, ya que dicho sistema natural tiene el derecho de garantizar su sobrevivencia. Como dice la Corte Constitucional (C.C., Sentencia C632/2011, Colom.): "En la actualidad, la naturaleza no se concibe únicamente como el ambiente y entorno de los seres humanos, sino también como un sujeto de derechos propios, que, como tal, deben ser protegidos y garantizados".

\section{Contaminación de las fuentes hídricas en el departamento del Chocó}

Las fuentes hídricas en el departamento del Chocó son las más afectadas por la contaminación ambiental, ocasionada por la minería ilegal que, además de contaminar los ríos y quebradas, está afectando el desarrollo de la vida de las comunidades negras e indígenas que habitan en la cuenca de los ríos, pues:

los cuerpos de agua en la región del Pacífico son fundamentales en la conformación de las comunidades, su vida, cultura y tradiciones. Los ríos y esteros son elementos fundamentales para la subsistencia de las comunidades que los habitan, sin embargo, la minería ilegal en la región ha generado una multiplicidad de riesgos para la población por la 
exploración y explotación indiscriminada de oro aluvial. (Defensoría del Pueblo, 2016, p. 15)

A lo anterior se le suma el conflicto armado, que es un factor determinante en la práctica de la minería ilegal, dado que los distintos grupos armados ilegales con presencia en el territorio utilizan esta actividad como una de sus fuentes de financiación y fortalecimiento de su estructura, a partir del control de la explotación con el cobro de "vacunas" o extorsiones a los dueños de los dragones, retroexcavadoras y dragas; así como cobros al gramaje, al combustible y a la utilización o explotación de un área determinada (Defensoría del Pueblo, 2016).

La llegada de retroexcavadoras, dragas y dragones al Chocó, patrocinadas por grupos armados ilegales, ha causado graves daños socio-ambientales en la región. De manera que la minería ilegal ha significado un nuevo espacio para estas organizaciones delictivas que se disputan el control del territorio no solo para los cultivos de uso ilícito y el tráfico de drogas, sino también para la explotación indiscriminada de oro y platino. La falta de oportunidades y la ausencia de estrategias en políticas públicas efectivas en el departamento de Chocó ha facilitado y allanado el camino para que la población se involucre en los cultivos de uso ilícito y la minería ilegal, lo que ha convertido dichas actividades en las únicas fuentes de subsistencia para las comunidades.

El auge de la minería en el departamento de Chocó ha estado en el centro de sus problemáticas recientes, no solo porque los grupos armados ilegales hayan encontrado en la actividad minera una fuente de financiación de sus empresas criminales, sino también porque fueron los propios mineros quienes, en asocio con los comerciantes que vieron incrementar sus negocios con el auge minero, promovieron y financiaron la conformación de grupos paramilitares en la zona buscando asegurar su 
actividad y sus intereses económicos. (Tribunal Superior de Medellín Sala de Conocimiento Justicia y Paz, 2017, p. 69)

El vertimiento de mercurio en los cuerpos de agua del departamento del Chocó, en el ejercicio de la minería, es uno de los principales agentes contaminantes, especialmente, en las riberas y afluentes del río Atrato, el más importante del departamento, según el Instituto de Investigaciones Ambientales del Pacífico (IIAP, 2016):
A lo largo de más de 60 años, se han liberado e incorporado grandes cantidades de mercurio a los ríos del departamento del Chocó, como resultado de la minería aurífera que se ha desarrollado históricamente en la región. La minería que se realiza en las riberas y afluentes del río Atrato, no solo se ha desarrollado con la finalidad de utilizar el agua en la fase de producción, sino también de verter a ellos todos los residuos generados, los cuales incluyen grandes cantidades de material particulado, lubricantes, grasa, aceites, metales (mercurio) y materiales orgánicos producidos en los campamentos. (p. 2)

\section{Según la Corporación Autónoma Regional para el Desarrollo Sostenible del} Chocó (Codecho, 2020):

La dinámica de las explotaciones mineras en el departamento del Chocó muestra de manera clara que la razón del grave daño ambiental que se causa al medio físico es la total ausencia de explotaciones que se realicen de manera técnica y bajo un esquema de responsabilidad social y ambiental [...]. La minería constituye la principal causa de la degradación de las cuencas hidrográficas, cuyos impactos afectan otros recursos naturales ligados al agua, como el suelo, la vegetación y la fauna, especialmente la ictiológica. (p. 67)

La situación descrita ha generado serios problemas en la salud en los miembros de las comunidades que se encuentran sobre la ribera del río Atrato, que utilizan el agua y los peces del río para consumo, los cuales, 
según un estudio del IIAP están contaminados con mercurio. Como dicen Mosquera, Senior y Casas (2012), las comunidades en el Chocó evidencian que los ríos están siendo contaminados, no hay peces y se generan enfermedades en quienes realizan trabajos relacionados con la minería. La extracción de oro a escala industrial emplea una gran cantidad de productos químicos que resultan dañinos para el medio ambiente (p. 75), y desconoce las técnicas tradicionales que han usado las comunidades de la zona.

Igualmente, según la investigación realizada por Medina, Ayala y Perea (2011):

El uso del mercurio en la minería en el Chocó está asociado con el proceso de beneficio metalúrgico, es ampliamente usado por los entables mineros mecanizados, pero debido a la forma empleada, la mayor parte se vierte a los ríos y es así como el mercurio se transforma en metilmercurio al asentarse en medios acuáticos, ocasionando problemas en el ambiente y a la salud de las comunidades que viven río abajo de las zonas mineras. (p. 2)

Lo anterior ha significado, en los últimos años, un aumento de los conflictos ambientales que involucran recursos hídricos en el departamento del Chocó. Entre 2004 y 2019 el Tribunal Contencioso Administrativo del Chocó conoció 19 acciones de grupos y 3 acciones populares que contenían un conflicto ambiental relacionado con fuentes hídricas (contaminación de ríos y quebradas), y entre 2017 y 2018 se interpusieron 13 acciones, como se observa en la tabla 1. 
Tabla 1. Conflictos ambientales judicializados relacionados con contaminación de fuentes hídricas en el departamento del Chocó

\begin{tabular}{|c|c|c|c|}
\hline Ubicación & $\begin{array}{l}\text { Recurso natural } \\
\text { afectado }\end{array}$ & $\begin{array}{l}\text { Tipo de acción } \\
\text { judicial/radicado }\end{array}$ & $\begin{array}{l}\text { Año de } \\
\text { radicación }\end{array}$ \\
\hline Quibdó & Río Cabi & $\begin{array}{c}\text { Acción popular: } \\
72001233100020040055000\end{array}$ & 2004 \\
\hline Nóvita & $\begin{array}{c}\text { Río Negro, quebrada } \\
\text { de San José y } \\
\text { quebrada de Nóvita }\end{array}$ & Acción de grupo: 20090692 & 2009 \\
\hline Quito & Río Quito & $\begin{array}{c}\text { Acción popular: } \\
\text { 27001233100120090021101 }\end{array}$ & 2009 \\
\hline $\begin{array}{c}\text { Cantón de San } \\
\text { Pablo }\end{array}$ & Río San Pablo & $\begin{array}{c}\text { Acción de grupo: } \\
2700123310002013004300\end{array}$ & 2013 \\
\hline $\begin{array}{c}\text { Unión } \\
\text { Panamericana }\end{array}$ & $\begin{array}{l}\text { Río de Unión } \\
\text { Panamericana }\end{array}$ & $\begin{array}{l}\text { Acción de grupo: } \\
27001233100020130015100\end{array}$ & 2013 \\
\hline $\begin{array}{c}\text { Unión } \\
\text { Panamericana }\end{array}$ & $\begin{array}{l}\text { Río de Unión } \\
\text { Panamericana }\end{array}$ & $\begin{array}{c}\text { Acción de grupo: } \\
2700123310002014004300\end{array}$ & 2014 \\
\hline Iró & Río Iró & $\begin{array}{c}\text { Acción de grupo: } \\
\text { 270012331000201300050 }\end{array}$ & 2013 \\
\hline Lloró & $\begin{array}{l}\text { Ríos Andágueda y } \\
\text { Atrato }\end{array}$ & $\begin{array}{c}\text { Acción de grupo: } \\
\text { 2700123310002016010600 }\end{array}$ & 2016 \\
\hline Bagadó & Río Andágueda & $\begin{array}{c}\text { Acción de grupo: } \\
\text { 27001333100020170050 }\end{array}$ & 2017 \\
\hline $\begin{array}{c}\text { Cantón de San } \\
\text { Pablo }\end{array}$ & Río San Pablo & $\begin{array}{c}\text { Acción de grupo: } \\
\text { 27001233100020170005300 }\end{array}$ & 2017 \\
\hline Medio Atrato & $\begin{array}{l}\text { Cuenca y afluentes } \\
\text { del río Atrato }\end{array}$ & $\begin{array}{l}\text { Acción de grupo: } \\
\text { 270012331000201700110 }\end{array}$ & 2017 \\
\hline $\begin{array}{l}\text { Departamento del } \\
\text { Chocó }\end{array}$ & $\begin{array}{l}\text { Río Atrato y sus } \\
\text { afluentes }\end{array}$ & $\begin{array}{c}\text { Acción de grupo: } \\
2700123310002017007600\end{array}$ & 2017 \\
\hline Atrato y Quibdó & $\begin{array}{l}\text { Río Atrato y sus } \\
\text { afluentes }\end{array}$ & $\begin{array}{c}\text { Acción de grupo: } \\
\text { 2700123310002017006800 }\end{array}$ & 2017 \\
\hline Condoto & Río Condoto & $\begin{array}{c}\text { Acción de grupo: } \\
\text { 270012331000201701500 }\end{array}$ & 2017 \\
\hline Tadó & $\begin{array}{l}\text { Río San Juan, } \\
\text { Mungarrá y sus } \\
\text { afluentes }\end{array}$ & $\begin{array}{c}\text { Acción de grupo: } \\
2700123310002017004200\end{array}$ & 2017 \\
\hline Condoto y río Iró & Ríos Condoto e Iró & $\begin{array}{c}\text { Acción de grupo: } \\
270012331000201700062\end{array}$ & 2017 \\
\hline $\begin{array}{l}\text { Departamento del } \\
\text { Chocó }\end{array}$ & $\begin{array}{l}\text { Cuenca y afluentes } \\
\text { del río Atrato }\end{array}$ & $\begin{array}{c}\text { Acción de grupo: } \\
2700123310002018001500\end{array}$ & 2018 \\
\hline $\begin{array}{l}\text { Departamento del } \\
\text { Chocó }\end{array}$ & Río Atrato & $\begin{array}{c}\text { Acción de grupo: } \\
2700123310002018003900\end{array}$ & 2018 \\
\hline Quito & $\begin{array}{l}\text { Río Quito y sus } \\
\text { afluentes }\end{array}$ & $\begin{array}{c}\text { Acción de grupo: } \\
2700123310002018001100\end{array}$ & 2018 \\
\hline
\end{tabular}

\section{Revista IUSTA}

ISSN: 1900-0448 | e-ISSN: 2500-5286 | DOI: https://doi.org/10.15332/25005286

N. 055 | julio-diciembre del 2021 


\begin{tabular}{|c|c|c|c|}
\hline Ubicación & $\begin{array}{c}\text { Recurso natural } \\
\text { afectado }\end{array}$ & $\begin{array}{c}\text { Tipo de acción } \\
\text { judicial/radicado }\end{array}$ & $\begin{array}{c}\text { Año de } \\
\text { radicación }\end{array}$ \\
\hline Quibdó & $\begin{array}{c}\text { Quebrada la Yesca y } \\
\text { sus afluentes }\end{array}$ & $\begin{array}{c}\text { Acción popular: } \\
\text { 27001233100020180000400 }\end{array}$ & 2018 \\
\hline Río Quito & $\begin{array}{c}\text { Río Quito, afluente } \\
\text { del río Atrato }\end{array}$ & $\begin{array}{c}\text { Acción de grupo: } \\
\text { 2700123310002018002200 }\end{array}$ & 2018 \\
\hline $\begin{array}{c}\text { Unión } \\
\text { Panamericana }\end{array}$ & $\begin{array}{c}\text { Rio de Unión } \\
\text { Panamericana }\end{array}$ & $\begin{array}{c}\text { Acción de grupo: } \\
\text { 27001333100020190000800 }\end{array}$ & 2019 \\
\hline
\end{tabular}

Fuente: elaboración propia mediante la información otorgada por el Tribunal Contencioso Administrativo del Chocó, en oficio n. 2057 del 13 de diciembre del 2019.

Los conflictos mencionados son de conocimiento de la jurisdicción contenciosa administrativa (Tribunal Contencioso Administrativo del Chocó), de los cuales 4 han sido fallados y 18 se encuentran en trámite, lo que muestra una evidente congestión judicial, pues, según la Ley 472 de 1998 en sus artículos 26, 28, 33 y 34, el término (una vez agotadas todas las atapas procesales) para que sean resueltos los conflictos ambientales que son sometidos a la vía judicial, a través de figuras constitucionales como las acciones de grupo y la acción popular, es de tres meses; sin embargo, hay conflictos de los relacionados en la tabla 1 que suman más de seis años sin una decisión resolutoria.

Este retraso judicial conlleva graves afectaciones a los derechos e intereses colectivos de los ciudadanos, pues, de conformidad con la Ley 472 de 1998, estas acciones populares y de grupo se ejercen con el propósito de evitar un daño contingente, hacer cesar el peligro, la amenaza y restituir las cosas a su estado anterior. De manera que si este tipo de acciones son utilizadas para acceder a la administración de justicia, en pro de la resolución de un conflicto ambiental, es porque las afectaciones al medio ambiente requieren una intervención urgente. Los retrasos de la justicia a la hora de decidir sobre estos conflictos afecta el ejercicio de los derechos colectivos de los ciudadanos e impide la intervención oportuna para evitar mayores daños al medio ambiente o a los recursos naturales involucrados. 
En la tabla 2 se describen algunas características de diez de los conflictos ambientales relacionados en la tabla 1, información que fue posible analizar gracias a la revisión de expedientes judiciales, específicamente del contenido de las demandas de acciones populares y de grupo que versan sobre contaminación a fuentes hídricas que reposan en el Tribunal Administrativo del Chocó. 
Tabla 2. Descripción de los conflictos ambientales judicializados en el departamento del Chocó, relacionados con contaminación de fuentes hídricas, conocimiento del Tribunal Contencioso Administrativo del Chocó.

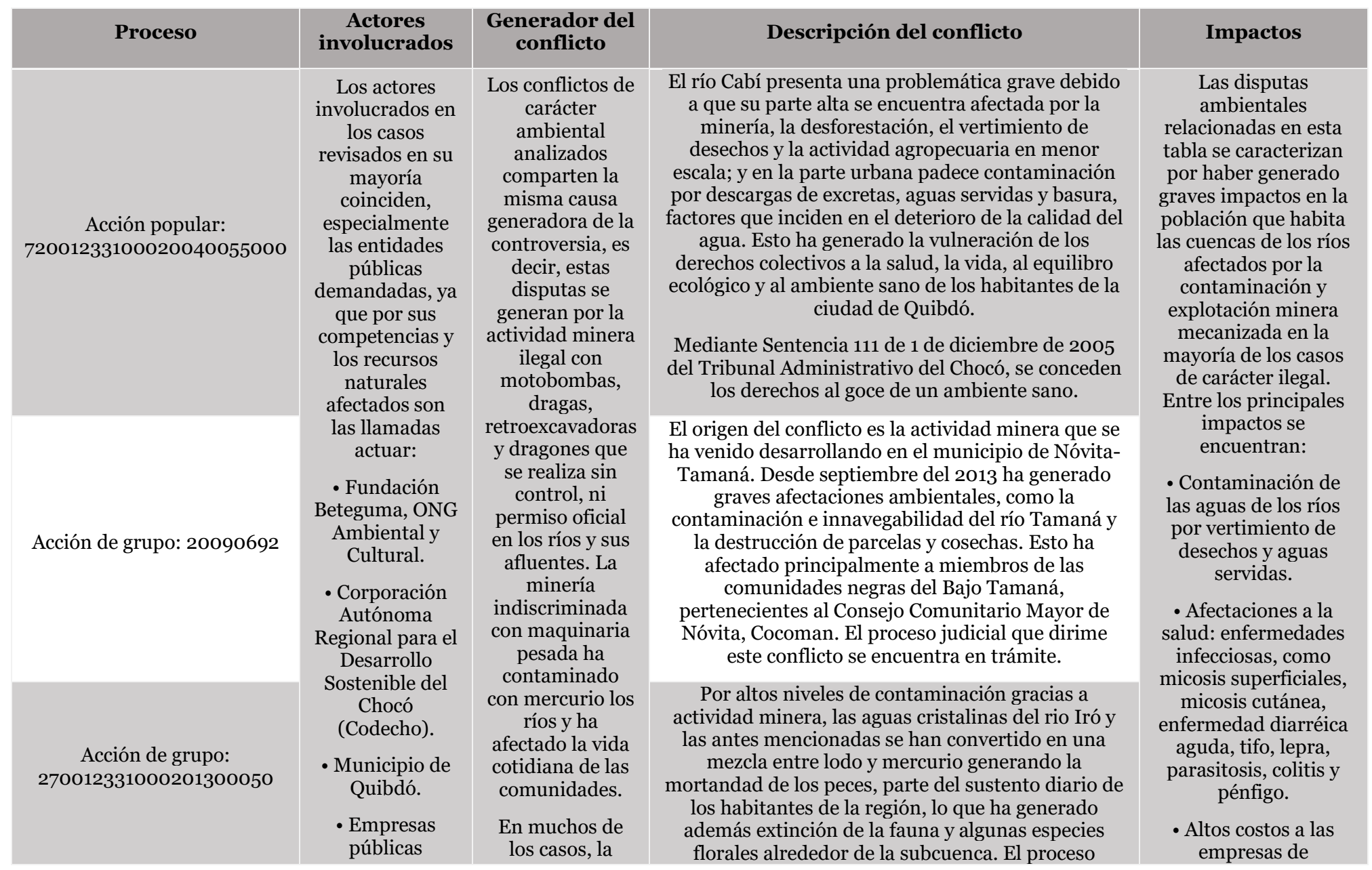

Revista IUSTA

ISSN: 1900-0448 | e-ISSN: 2500-5286 | DOI: https://doi.org/10.15332/25005286

N.0 55 | julio-diciembre del 2021 


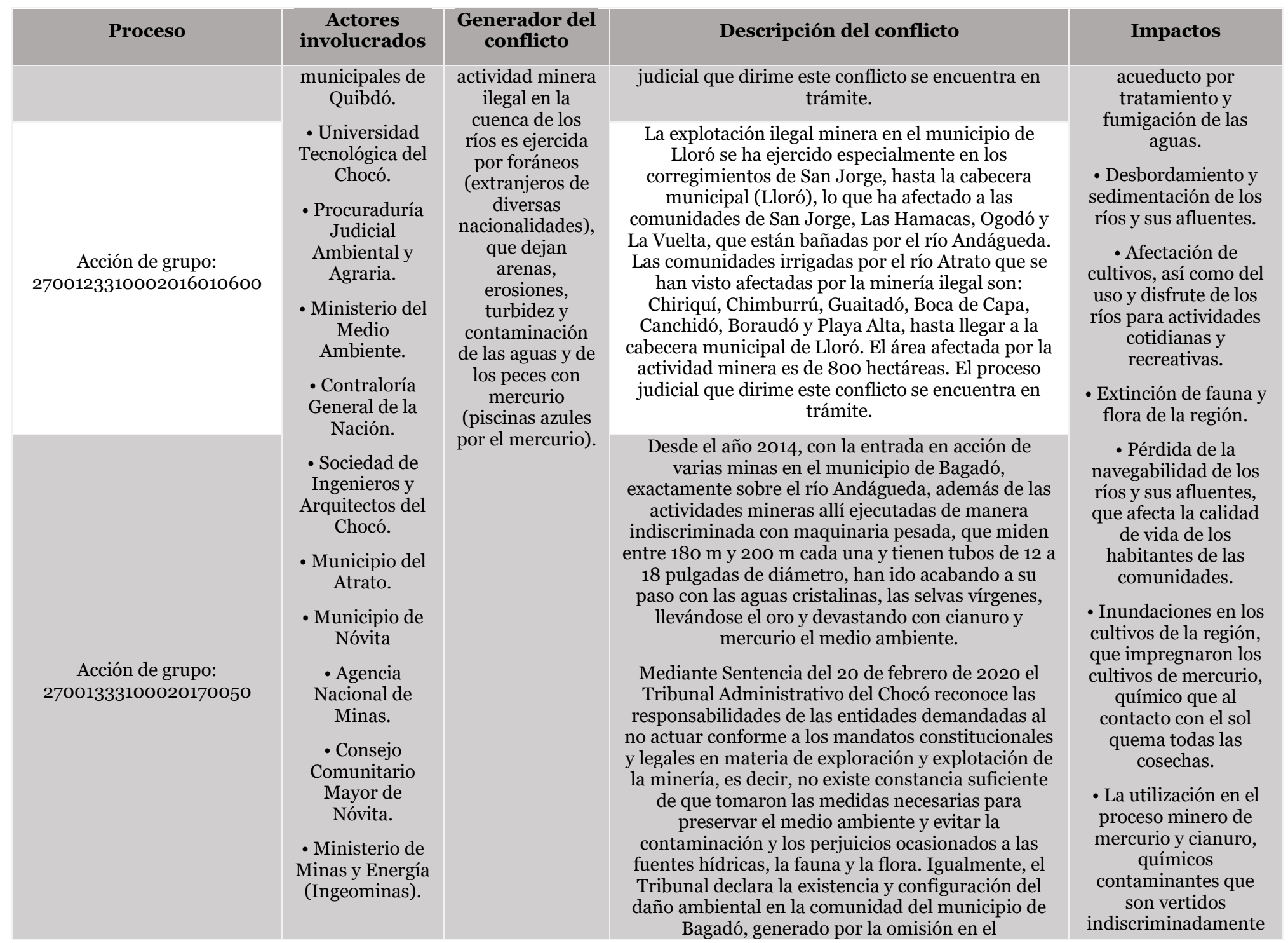

Revista IUSTA

ISSN: 1900-0448 | e-ISSN: 2500-5286 | DOI: https://doi.org/10.15332/25005286

N.0 55 | julio-diciembre del 2021 


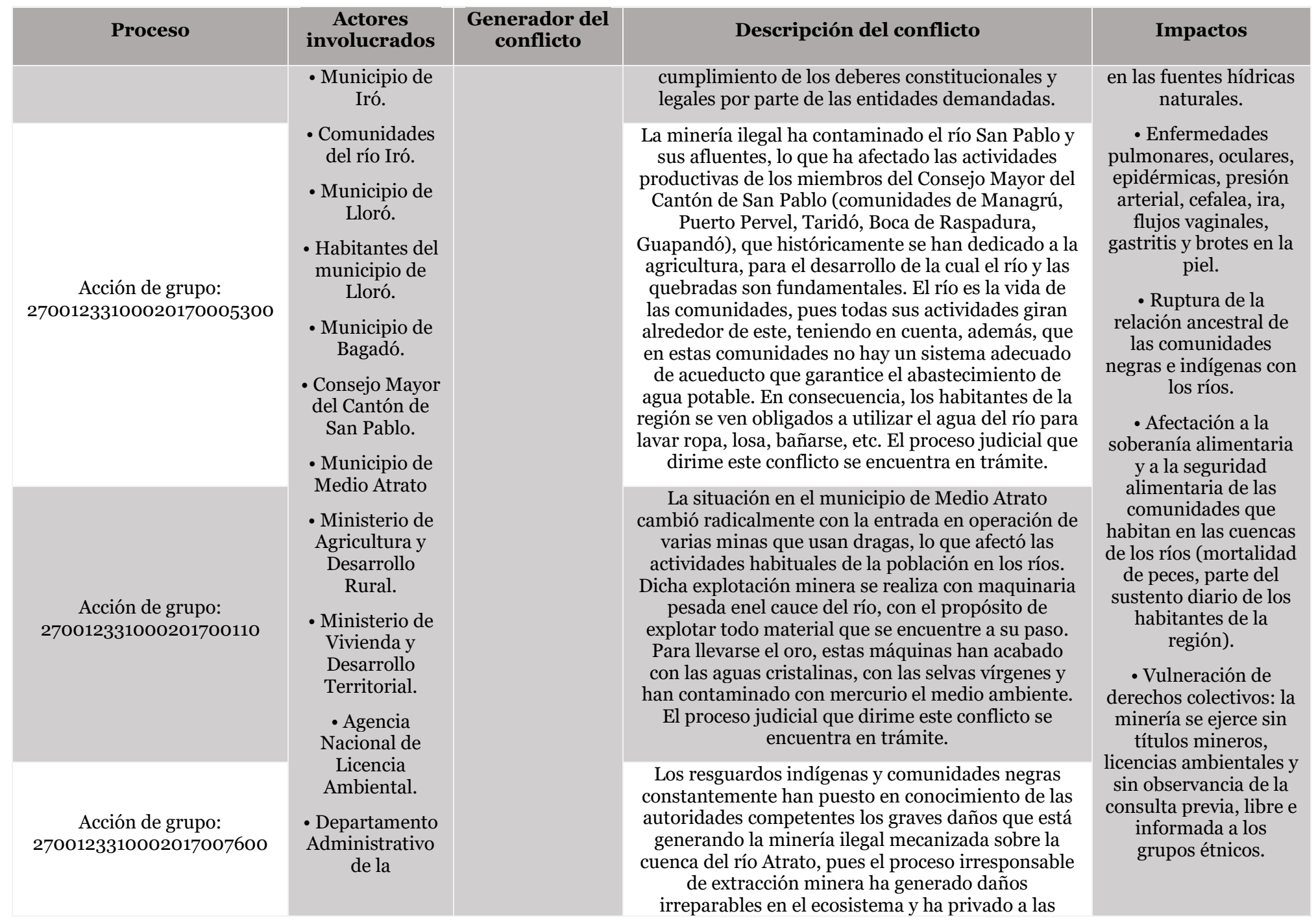

Revista IUSTA

ISSN: 1900-0448 | e-ISSN: 2500-5286 | DOI: https://doi.org/10.15332/25005286

N.0 55 | julio-diciembre del 2021 


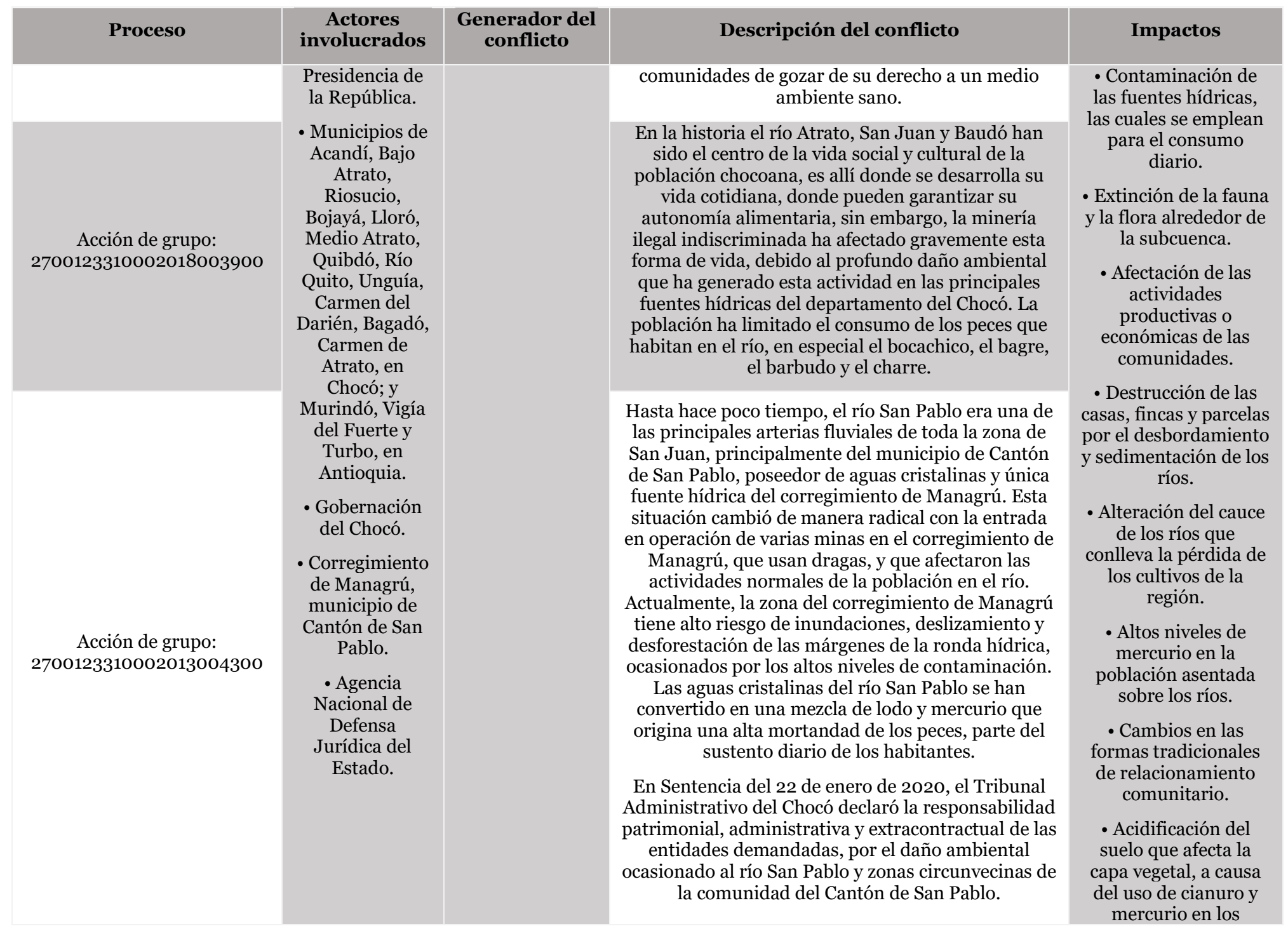

Revista IUSTA

ISSN: 1900-0448 | e-ISSN: 2500-5286 | DOI: https://doi.org/10.15332/25005286

N.0 55 | julio-diciembre del 2021 


\begin{tabular}{|c|c|c|c|c|}
\hline Proceso & $\begin{array}{c}\text { Actores } \\
\text { involucrados }\end{array}$ & $\begin{array}{l}\text { Generador del } \\
\text { conflicto }\end{array}$ & Descripción del conflicto & Impactos \\
\hline & & & & $\begin{array}{l}\text { procesos de limpieza y } \\
\text { extracción del metal. } \\
\text { - Alteración del paisaje } \\
\text { y destrucción del } \\
\text { bosque natural por la } \\
\text { actividad minera } \\
\text { ilegal. } \\
\text { - La actividad minera } \\
\text { en los ríos y sus } \\
\text { afluentes se realiza sin } \\
\text { considerar las } \\
\text { medidas ambientales } \\
\text { necesarias, tales como: } \\
\text { pozos de } \\
\text { sedimentación para } \\
\text { retirar los sólidos } \\
\text { presentes en los } \\
\text { vertimientos } \\
\text { derivados de la } \\
\text { explotación de oro. }\end{array}$ \\
\hline
\end{tabular}

Fuente: elaboración propia a partir de la información recolectada en los expedientes judiciales (contenido de las demandas) de acciones populares y de grupo que reposan en el Tribunal Contencioso Administrativo del Chocó. 
La utilización de la vía judicial como mecanismo de resolución de conflictos socio-ambientales no siempre resulta suficiente, pues los procesos ante lo contencioso administrativo son acusados de falta de celeridad procesal, y si bien la congestión judicial es un mal generalizado en la administración de justicia, reviste agravación cuando está de por medio la resolución de asuntos concernientes al medio ambiente (Rodríguez, 2019). Además, los fallos proferidos en materia ambiental no corresponden a pronunciamientos de jueces especializados, de manera que se podría reclamar un desconocimiento profundo de los administradores de justicia sobre este tipo de conflictos. Como puede verse en la tabla 2, los procesos que versan sobre conflictos ambientales pueden terminar siendo fallados hasta seis años después de interpuesta la acción judicial.

Como dice Boaventura de Sousa (1991), el sistema jurídico de los países capitalistas se encuentra en crisis desde sus inicios, a causa de la progresiva imposibilidad del sistema judicial para enfrentar el aumento de ciudadanos que ponen el sistema en marcha, el cual se encuentra debilitado debido a los escasos recursos técnicos, financieros y profesionales con los que funciona. Para algunos la solución reside en el aumento cuantitativo de los recursos para la administración de justicia, sin embargo, esta opción se revela cada vez más inviable por la crisis financiera de los Estados, de manera que la superación de dicha crisis solo será posible mediante la reforma estructural del sistema judicial, lo que implica alteraciones cualitativas de sus modos actuales de funcionamiento. Para solucionar este tema, Rodríguez (2019) propone dos soluciones: 1) la creación de una jurisdicción ambiental, que requiere reformas constitucionales y legales que modificarían todo el sistema judicial colombiano; y 2) una justicia ambiental especializada en sede de lo contencioso administrativo, la cual solo requeriría reformas legales y no 
constitucionales. Estas propuestas si bien son viables y necesarias en el marco de la crisis medioambiental que vive el país, solo se concentran en la vía judicial como mecanismo de resolución de conflictos. No obstante, existen otros iguales o más efectivos, como son los mecanismos propios de resolución de conflictos de los grupos étnicos, especialmente los de las comunidades negras, que les han permitido resolver pacíficamente sus controversias socio-ambientales - esta podría ser, al menos, una vía para los conflictos internos-.

En el caso particular del departamento del Chocó, los mecanismos judiciales son limitados para la población local, ya que los centros judiciales se encuentran en los cascos urbanos, que en muchas ocasiones son de difícil acceso para los pobladores rurales. A esto se suma la presencia de los grupos armados ilegales que imponen sus propias normas $\mathrm{y}$ formas de solucionar los conflictos, y que intervienen constantemente en las controversias de las comunidades, lo que ha debilitado la autonomía de las autoridades étnico territoriales, como los consejos comunitarios y los resguardos indígenas. La International Crisis Group (2017) afirma que:

Para los grupos armados de Colombia, la resolución de disputas a nivel local es uno de los medios más eficaces de lograr el apoyo de la comunidad y legitimidad. Todos los grupos examinados en este informe resuelven disputas en los territorios que controlan, si bien en general lo hacen con un estilo de justicia sumamente autoritario. Para adquirir legitimidad a nivel local, el Estado debe ofrecer o mejorar sus propios mecanismos, pues el acceso local a los mecanismos judiciales estatales es insuficiente, y en algunas áreas inexistente. En 2014, el Ministerio Público solo tenía oficinas en 453 municipios (de 1101); la mayoría están en centros urbanos de difícil acceso para los pobladores rurales. Se necesitan alternativas al sistema de tribunales, y en algunos lugares ya existen modelos. (p. 24) 
Para Criado (2019):

La dificultad de acceso al sistema formal de justicia por parte de las comunidades rurales en Colombia es una característica estructural del Estado, que está relacionada con los procesos de poblamiento y articulación del espacio nacional que ha producido amplias franjas territoriales desintegradas de los mercados y las vías de comunicación nacionales, sin una presencia suficiente de las instituciones estatales para hacer valer el orden jurídico. En estos territorios [...] se han desarrollado órdenes sociales comunitarios de origen étnico y campesino al mismo tiempo de formas locales de poder armado de facto que sustituyen al Estado en la función de resolver los conflictos y preservar el orden. (p. 249)

Ahora bien, la tabla 2 también permite evidenciar que gran parte de los conflictos ambientales en el departamento del Chocó están asociados con actores institucionales responsables de ejercer competencias de cuidado del medio ambiente y de los derechos de las comunidades étnicas. Sin embargo, otros conflictos implícitos o derivados de la acción omisiva que llega hasta los estrados judiciales, como las disputas internas por arrendamiento de terrenos a terceros para realizar actividad minera o permisos para talar y ocupar terrenos e instalar campamentos para los entables mineros, no quedan evidenciados en los procesos judiciales, aunque sí están presentes en la vida cotidiana de los territorios colectivos. Precisamente, para estos desacuerdos hay una vía poco explorada en el caso de las comunidades negras, que podría prevenir la interposición de acciones que toman largos periodos para ser resueltas.

Recientemente, se está reconociendo que las comunidades negras que habitan en esta región del país han utilizado históricamente sus propios mecanismos de resolución de conflictos, a través de los cuales han logrado resolver controversias de todo tipo, incluyendo las ambientales. De 
manera que es urgente que el Estado Colombiano, primero, reconozca y garantice el ejercicio de los mecanismos ancestrales de las comunidades negras, los cuales son una expresión de su derecho propio y una herramienta efectiva a la hora de resolver controversias de tipo ambiental, bajo el liderazgo de los consejos comunitarios; segundo, es preciso que se amplíe la cobertura de la justicia, de manera que los colombianos de las zonas rulares tengan un fácil acceso a esta; tercero, es importante que se constituya una jurisdicción especial ambiental que permita que los procesos que versen sobre conflictos relacionados con el medio ambiente logren una mayor celeridad y efectividad.

\section{Conclusiones}

Los conflictos analizados en este artículo muestran el tipo de conflictos ambientales que son judicializados en el departamento del Chocó, en su mayoría ocasionados por los graves impactos que produce la práctica indiscriminada de la minería, especialmente la de tipo aluvial. Asimismo, se constató que las instituciones estatales han sido un actor determinante en estos conflictos, al ser demandadas por sus actos omisivos frente a sus funciones constitucionales y legales. Sin embargo, muchos de los conflictos analizados no han sido fallados dentro de los términos legales y eso se debe a una clara congestión judicial.

La congestión judicial que genera la falta de celeridad en los procesos ha sido un tema discutido y evidenciado en diferentes escenarios, es claro que muchos sistemas judiciales latinoamericanos y especialmente el colombiano pasan, desde sus inicios, por una crisis, como afirma Boaventura de Sousa (2019). Los retrasos de la justicia a la hora de decidir sobre los conflictos socioambientales afectan el ejercicio de los derechos colectivos de los ciudadanos y comunidades e impide la intervención a tiempo para evitar mayores daños al medio ambiente o a los recursos 
naturales involucrados, de manera que es urgente que se constituya una jurisdicción especial ambiental que permita que los procesos que versen sobre conflictos ambientales logren una mayor celeridad y efectividad. No obstante, la escalada exponencial de los conflictos ambientales en Colombia ha generado que cada vez más sean judicializados, especialmente mediante acciones constitucionales que pretenden de manera urgente detener o prevenir las afectaciones sobre el medio ambiente.

Por otra parte, si bien la vía judicial es un mecanismo para la resolución de los conflictos ambientales, no todos los conflictos de este tipo son llevados hasta los estrados judiciales, especialmente los que emergen en los territorios colectivos de comunidades negras, como las disputas internas por arrendamiento de terrenos a terceros para realizar actividad minera o permisos para talar y ocupar terrenos e instalar campamentos para los entables mineros. En los territorios colectivos de comunidades negras es común entregar terrenos familiares a terceros para que realicen minería por un porcentaje, que se aplica sobre el mineral extraído, estos acuerdos suscitan conflictos que por lo general son tratados por las autoridades étnico territoriales como los consejos comunitarios. Antes de que existiera esta figura, establecida por la Ley 70 de 1993 y el Decreto 1745 de 1995, los conflictos mencionados eran resueltos mediante mecanismos propios de las comunidades negras, que siguen siendo utilizados en diferentes poblaciones del departamento del Chocó. Por lo tanto, si bien la intervención del Estado es necesaria en la resolución de los conflictos ambientales, no todos están a su alcance, de ahí la importancia y trascendencia de los mecanismos propios de resolución de conflictos de las comunidades negras, que en muchos territorios del departamento del Chocó son utilizados por los consejos comunitarios. 
La afectación del recurso hídrico debe asumirse como un problema grave para la supervivencia de las comunidades negras e indígenas en el departamento del Chocó, y en general de su población, que sustentan parte de su identidad y supervivencia en el uso y aprovechamiento del agua, considerada más que como un recurso para extraer como un elemento de la interrelación que existe entre el medio ambiente y la vida misma de las comunidades negras. También es urgente analizar si la práctica judicial que instrumentaliza las sentencias o decisiones judiciales, como el mecanismo para exigir el cumplimiento de las actividades misionales de diferentes entidades estatales, es garantía de la protección oportuna de los recursos naturales y en definitiva de los derechos de las comunidades étnicas, porque no obstante el curso y/o fallo en algunos eventos de acciones judiciales, los ríos del Chocó siguen llenos de mercurio. La crisis ambiental por la que atraviesa el departamento del Chocó hace necesario que la vía judicial y otras formas de resolver los conflictos, como los mecanismos propios de las comunidades negras, coexistan y se conviertan en vías efectivas, de manera que sea posible encontrar herramientas adecuadas para detener las afectaciones ambientales y sociales que generan este tipo de conflictos, como es el caso de las comunidades negras e indígenas, que debido a los graves daños ambientales ocasionados por la minería ilegal e industrializada han perdido sus medios de subsistencia como la caza, la agricultura, la pesca e incluso la minería como práctica ancestral, en el caso particular de las comunidades negras.

\section{Referencias}

Briceño, A. (2017). Responsabilidad y protección del ambiente: La obligación positiva del Estado. Universidad Externado de Colombia. 
Cerrillo, A. (2016). Los diez conflictos ambientales más importantes del planeta. https://www.lavanguardia.com/natural/20160603/402253210855/conflictosambientales-litigios-ambientales-atlas-global-de-justicia-ambiental.html

Colombia. Decreto 1745 de 1995. Por el cual se reglamenta el Capítulo III de la Ley 70 de 1993, se adopta el procedimiento para el reconocimiento del derecho a la propiedad colectiva de las "Tierras de las Comunidades Negras" y se dictan otras disposiciones. Octubre 12 de 1995. Ministerio del Interior.

Colombia. Ley 472 de 1998. Por la cual se desarrolla el artículo 88 de la Constitución Política en relación con el ejercicio de las acciones populares y de grupo y se dictan otras disposiciones. Agosto 5 de 1998. D.O. núm. 43.357.

Colombia. Ley 70 de 1993. Por la cual se desarrolla el artículo transitorio 55 de la Constitución Política. Agosto 27 de 1993. D.O. núm. 41.013.

Corporación Autónoma Regional para el Desarrollo Sostenible del Chocó (Codecho). (2020). Plan de Acción Institucional Oportunidad y Desarrollo Sostenible para las Subregiones 2020-2023.

https://www.codechoco.gov.co/sites/Documentos/Planeacion/PAI 2020 2023.p df

Corte Constitucional de Colombia [C.C.], enero 26, 2009, M.P.: M. J. Cepeda, Auto oo5 de 2009, [Colom.].

Corte Constitucional de Colombia [C.C.], agosto 24, 2011, M.P.: L. E. Montealegre, Sentencia C-632 de 2011, [Colom.].

Corte Constitucional de Colombia [C.C.], octubre 6, 2016, M.P.: J. I. Palacio, Sentencia T622 [Colom.].

Criado, M. (2019). Territorios y acceso a la justicia en el posconflicto colombiano. Estudio sobre la conflictividad y los mecanismos de resolución de conflictos en las zonas rurales de Guapi, Cauca. Universidad Externado de Colombia.

De Sousa, B. (Ed.). (1991). Estado, derecho y luchas sociales. Instituto Latinoamericano de Servicios Legales Alternativos (ILSA).

Defensoría del Pueblo. (2016). Problemática humanitaria en la Región Pacífica colombiana.

https://www.acnur.org/fileadmin/Documentos/Publicaciones/2017/11053.pdf

Revista IUSTA

ISSN: 1900-0448 | e-ISSN: 2500-5286 | DOI: https://doi.org/10.15332/25005286

N. ${ }^{0} 55$ | julio-diciembre del 2021 
Güiza, L., Londoño, B., Rodríguez, C. y Zuluaga, J. (2015). Las agendas interinstitucionales ambientales: un instrumento para la resolución de conflictos ambientales. Revista de Estudios Sociales. (53), 29-42. doi: http://dx.doi.org/10.7440/res53.2015.02

Hernández, S. y Mendoza, T. (2018). Metodología de la investigación. Las rutas cuantitativa, cualitativa y mixta. McGraw Hill.

Hinestroza, C., Mena, M. y Tello, M. (2019). Diferencias entre semejantes: apropiación del concepto de territorio desde la diversidad étnica de Colombia. En P. García (Ed.), Lecturas sobre derechos de tierras (pp. 133-192). Universidad Externado de Colombia.

Instituto de Investigaciones Ambientales del Pacífico (IIAP). (2016). Contenido de mercurio en músculos de algunas especies de importancia socioeconómica, en la cuenca del río Atrato. Quibdó.

International Crisis Group. (2017, 19 de octubre). Los grupos armados de Colombia y su disputa por el botín de la paz. Informe sobre América Latina n. ${ }^{\circ} 63$. https://www.crisisgroup.org/es/latin-america-caribbean/andes/colombia/63colombias-armed-groups-battle-spoils-peace

Londoño, V. M. y Polindara, R. C. (2019). Entre la venta del recurso forestal y la supervivencia comunitaria. En G. Rodríguez y A. Ibáñez (eds.), Las disputas ambientales en Colombia (pp. 61-87). Ibáñez.

Medina, F. M., Ayala, H. M. y Perea, J. (2011). Determinación de la contaminación mercurial en personas vinculadas con la minería de oro en el Distrito Minero del San Juan, departamento del Chocó, Colombia. Bioetnia, 8(2), 195-206.

Melo, D. (2015). La minería en chocó, en clave de derechos. Investigación y propuestas para convertir la crisis socio ambiental en paz y justicia territorial. Centro de Estudios para la Justicia Social Tierra Digna.

Mosquera, L. y González Zapata, A. (2020). Las brechas socioeconómicas y su relación con la corrupción: elementos clave a la hora de formular políticas públicas. Revista IUSTA, (52), 103-122. doi: https://doi.org/10.15332/25005286.5485 
Mosquera, M., Senior, S y Casas, S. (2012). Impactos de la minería en el cuerpo y la vida de la mujer. En T. Londoño, S. Güiza y A. Muñoz (Eds.), Conflictos ambientales en Colombia: retos y perspectivas desde el enfoque de DDHH y la participación ciudadana (pp. 73-78). Universidad del Rosario.

Palomares, J. (2015). El carácter vinculante de la jurisprudencia constitucional en el derecho alemán. Via Inveniendi et Iudicandi, 10(2), 29-56.

Pardo, N. (2014). Un recorrido por los derechos colectivos en la jurisprudencia argentina. Via Inveniendi et Iudicandi, 9(1), 32-49.

Rodríguez, G. (2016). Los conflictos ambientales en Colombia y su incidencia en los territorios indígenas. Universidad del Rosario.

Rodríguez, J. (2019). El Imperativo de fortalecer el sistema judicial colombiano en materia ambiental. En G. Rodríguez y A. Ibáñez (eds.), Las disputas ambientales en Colombia (pp. 61-87). Ibáñez.

Rodríguez, G. e Ibáñez, A. (2019). Las disputas ambientales en Colombia. Ibáñez.

Tribunal Contencioso Administrativo del Chocó. Oficio n. 2057 del 13 de diciembre de 2019.

Tribunal Contencioso Administrativo del Chocó. Radicado n. 20090692 de 2009.

Tribunal Contencioso Administrativo del Chocó. Radicado n. ${ }^{\circ}$ 27001233100120090021101 de 2009.

Tribunal Contencioso Administrativo del Chocó. Radicado n. ${ }^{\circ}$ 2700123310002013004300 de 2013.

Tribunal Contencioso Administrativo del Chocó. Radicado n. ${ }^{\circ}$ 27001233100020130015100 de 2013.

Tribunal Contencioso Administrativo del Chocó. Radicado n. ${ }^{\circ}$ 2700123310002014004300 de 2014.

Tribunal Contencioso Administrativo del Chocó. Radicado n. 270012331000201300050 de 2013.

Tribunal Contencioso Administrativo del Chocó. Radicado n. ${ }^{\circ}$ 2700123310002016010600 de 2016. 
Tribunal Contencioso Administrativo del Chocó. Radicado n. 27001233100020170005300 de 2017.

Tribunal Contencioso Administrativo del Chocó. Radicado n. 270012331000201700110 de 2017.

Tribunal Contencioso Administrativo del Chocó. Radicado n. ${ }^{\circ}$ 2700123310002017007600 de 2017.

Tribunal Contencioso Administrativo del Chocó. Radicado n. ${ }^{\circ}$ 2700123310002017006800 de 2017.

Tribunal Contencioso Administrativo del Chocó. Radicado n. 270012331000201701500 de 2017.

Tribunal Contencioso Administrativo del Chocó. Radicado n. ${ }^{\circ}$ 2700123310002017004200 de 2017.

Tribunal Contencioso Administrativo del Chocó. Radicado n. 270012331000201700062 de 2017.

Tribunal Contencioso Administrativo del Chocó. Radicado n. ${ }^{\circ} 2700123310002018001500$ de 2018.

Tribunal Contencioso Administrativo del Chocó. Radicado n. ${ }^{\circ}$ 2700123310002018003900 de 2018.

Tribunal Contencioso Administrativo del Chocó. Radicado n. 2700123310002018001100 de 2018.

Tribunal Contencioso Administrativo del Chocó. Radicado n. ${ }^{\circ}$ 27001233100020180000400 de 2018.

Tribunal Contencioso Administrativo del Chocó. Radicado n. ํ 2700123310002018002200 de 2018.

Tribunal Contencioso Administrativo del Chocó. Radicado n. ${ }^{\circ} 27001333100020170050$ de 2017.

Tribunal Contencioso Administrativo del Chocó. Radicado n. 27001333100020190000800 de 2019.

Revista IUSTA

ISSN: 1900-0448 | e-ISSN: 2500-5286 | DOI: https://doi.org/10.15332/25005286

N. ${ }^{\circ} 55$ | julio-diciembre del 2021 
Tribunal Contencioso Administrativo del Chocó. Radicado n.

72001233100020040055000 de 2004.

Tribunal de lo Contencioso Administrativo del Chocó. Sentencia 111 de 2005.

Tribunal Superior de Medellín Sala de Conocimiento Justicia y Paz. (2017). Radicados: 0016000253-2008-83308, 0016000253-2010-84398, 0016000253-2006-80893. https://www.fiscalia.gov.co/colombia/wp-content/uploads/2017/02/2017-01-30rodrigo-zapata-sierra-y-otros-primera.pdf

Valencia, J. (2011). El derecho de acceso a la justicia ambiental y sus mecanismos de aplicación en Colombia. [Tesis doctoral, Universidad de Alicante]. Repositorio institucional Universidad de Alicante.

https://rua.ua.es/dspace/bitstream/10045/24617/1/Tesis_Javier_Gonzaga_Valen cia.pdf

Walter, M. (2009). Conflictos ambientales, socioambientales, ecológico distributivos, de contenido ambiental. Reflexionando sobre enfoques y definiciones. CIP-Ecosocial. Boletín ECOS, 6, 2-9. 